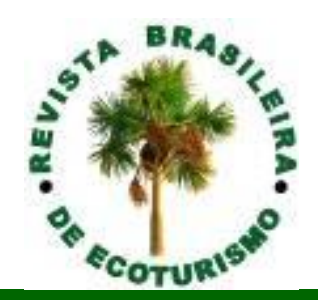

\title{
A percepção da comunidade de Perobas (RN) sobre o desenvolvimento do turismo
}

\author{
The perception of Perobas community (RN, Brazil) on the development \\ of tourism
}

\author{
Wagner Araújo Oliveira, Clébia Bezerra Silva
}

\section{RESUMO}

O presente estudo tem como objetivo avaliar a percepção da comunidade de Perobas com relação ao desenvolvimento do turismo nos seus recifes de corais. Esta comunidade situase no município de Touros/RN, distante aproximadamente $90 \mathrm{~km}$ da Capital do Estado Natal, o qual faz parte da área de influência direta da Área de Proteção Ambiental dos Recifes de Corais juntamente com os municípios de Maxaranguape e Rio do Fogo. Os procedimentos metodológicos consistiram na revisão da literatura, aplicação de questionários, visita in loco e capturas de imagens. Os resultados obtidos mostram que a comunidade tem uma visão do turismo como uma atividade alternativa para ganhos econômicos e dá uma importância significativa ao parracho, pois a partir das atividades que ocorrem no local como o turismo e a pesca, as famílias tiram seu próprio sustento por meio da geração de emprego e renda. Logo, conclui-se que a comunidade tem alguns entraves quanto ao desenvolvimento do turismo e da conservação e manutenção dos recifes de corais. Portanto, ver-se a necessidade de um planejamento correto e uma gestão eficaz, capaz de desenvolver o turismo de forma sustentável e garantir a preservação e a conservação dos recifes de corais e a distribuição dos benefícios gerados para todos os atores envolvidos de forma equitativa.

PALAVRAS-CHAVE: Planejamento; Percepção; Turismo; Perobas.

\section{ABSTRACT}

The aim of the present study was to evaluate the perception of the Perobas community regarding the development of tourism in the Perobas coral reefs. The Perobas community is located in Touros/RN, $90 \mathrm{~km}$ away from the province capital, Natal, which, along with the municipalities of Maxaranguape and Rio do Fogo are part of the direct influence area of the Environmental Protection Area Coral Reef. The methodological process consisted in a literature review, questionaries, on-site visit and snapshots. The results show that the community seems tourism as an alternative activity for economic gain, and gives a significant importance to the Parrachos, because activities such as fishing and tourism guarantees the earnings by the generation of jobs and income. Finally, it is concluded that the community have some obstacles in the development of tourism, conservation and maintenance of coral reefs, therefore, there is a need for a plan regarding a correct and an effective management able to develop a sustainable form of tourism, ensuring the preservation and conservation of coral reefs and an equally distribution of the benefits generated for the agents involved.

KEYWORDS: Planning; Perception; Tourism; Perobas. 


\section{Introdução}

O fluxo turístico tem aumentado em áreas de recifes de corais pela beleza, variedade marinha e praias protegidas que estes apresentam. Os recifes de corais são lugares de prática do lazer para turistas, banhistas, mergulho livres e autônomos. No entanto, a falta de planejamento é um dos principais indicadores que contribui para a degradação dos ambientes recifais.

Dessa forma, a conservação e preservação são de suma importância, pois há a necessidade de proteção do meio ambiente e da diversidade biológica marinha, como também há comunidade residente, que depende das atividades econômicas, como a pesca e o turismo. A destruição dos recifes gera uma perda significativa de emprego no turismo, na recreação marinha e na indústria da pesca, além de comprometer a conservação das espécies marinhas (RANIERO, 2007).

Diante disso, o turismo é uma atividade econômica que vem ganhando destaque em nível global, capaz de gerar inúmeros impactos positivos e negativos nas localidades onde está inserido. Nesse sentido, percebe-se que planejar o turismo não é uma atividade fácil, uma vez que, de acordo com Santos (2004), o planejamento consiste em um processo contínuo que envolve a obtenção, a organização e a sistematização das informações, por meio de procedimentos metodológicos a fim de alcançar um objetivo em um determinado prazo.

O desenvolvimento turístico nos países da região intertropical depende dos ambientes recifais para geração de divisas (MELO et al., 2005). Contudo, as atividades antrópicas, como coleta de corais, pesca desordenada, desenvolvimento e ocupação costeira, deposição de lixos nas margens dos recursos hídricos e turismo desordenado, constituem ameaças constantes a este ecossistema (VERDASCA, 2008). Esse turismo, nessas regiões e em todo o mundo, vem crescendo e gerando muitas riquezas econômicas. Já em locais como Caribe, Florida Keys National Marine Sanctuary Park (EUA), Parque Marinho da Grande Barreira de Recifes - GBR (AUS), a geração de divisas através do turismo marinho apresenta-se em grande escala, gerando bilhões de dólares (KUNZMANN, 2004), inclusive no Brasil com o Parque Nacional Marinho de Fernando de Noronha (PARNAMAR-FN).

Todavia, os ambientes marinhos e costeiros do Brasil têm sofrido um processo de degradação nos últimos anos, , gerado pela crescente pressão da atividade humana sobre os recursos naturais marinhos (SANTOS; CÂMARA, 2002). Eles correspondem a $3.555 .796 \mathrm{~km}$, dos quais $54.390 \mathrm{~km}$ fazem parte de alguma unidade de conservação (UC), tanto de proteção integral quanto de uso sustentável, totalizando 120 UCs, correspondendo a $1,57 \%$ das UCs. 0 ecossistema marinho vem sendo utilizado de várias maneiras, sobretudo, para sobrevivência das comunidades costeiras, como apontado por Prates (2012, p. 12),

No ambiente marinho a densidade demográfica de cerca de 87 habitantes por quilômetro quadrado, índice cinco vezes superior à média do território nacional. Essa estreita faixa continental abrange 17 estados e, ainda, concentra 13 das 27 capitais brasileiras, algumas das quais, regiões metropolitanas onde vivem milhões de pessoas, um indicador do alto nível de pressão antrópica a que seus recursos naturais estão submetidos. 
Esse contingente populacional associado a instrumentos efetivos de ordenamento do espaço e ao uso desenfreado dos recursos naturais tem provocado à desestruturação dos ecossistemas e a perda de qualidade ambiental, muitas vezes desorganizando as maneiras tradicionais de vida das comunidades. $\mathrm{Na}$ região Nordeste do Brasil, os ambientes recifais estão entre os ecossistemas mais ameaçados de sofrerem interferências múltiplas decorrentes das pressões humanas (LEÃO et al., 2003). Sendo assim, percebe-se que o meio marinho continua sem atenção adequada por parte dos governos, dizimando progressivamente sem que nenhuma medida para coibir seu impacto negativo seja tomada pelo Governo Federal (PEDRINI et al., p. 699, 2007), destarte, nota-se que esses ambientais merecem ser preservados dada a sua importância.

Assim sendo, percebe-se que o planejamento envolve a participação de vários atores que estejam ligados direto ou indiretamente a atividade turística, é o caso do poder público, iniciativa privada e comunidade local. Dessa forma, é necessário que todos estejam conscientes dos impactos que o turismo provoca, sejam eles negativos ou positivos e tenham conhecimento do que seja atividade turística.

No tocante à percepção, outro fator importante para o planejamento turístico, principalmente das comunidades diretamente afetadas pela atividade, Oliveira (2006, p. 3) traz o seguinte entendimento.

[...] a percepção das pessoas, sobre determinado assunto, é sempre carregada de uma visão própria de cada indivíduo, formada a partir de variáveis como meio social, história de vida, nível de escolaridade, religião, atividade econômica, entre outros. Consequentemente, cada indivíduo percebe o mundo qualitativa, efetiva e valorativamente, e é a partir dessa percepção que define seu modo de relação com a sociedade.

Somando a isso, tem-se a afirmação de que "apesar da percepção ser individual, ao se analisar esta impressão de uma população, de modo geral, pode ser considerado o entendimento comum, ou seja, a vontade da maioria". (CARVALHO, 2010, p.471). Para tanto, visualiza-se que a percepção da comunidade sobre o turismo é um conhecimento necessário para o planejamento turístico, pois a partir disso se terá uma análise de como a comunidade está se comportando diante do fenômeno do turismo, já que sua satisfação é primordial para desenvolver a atividade.

Pesquisas nesse sentido ganham relevo na universidade. Vários pesquisadores, sobretudo da área do turismo, procuraram realizar pesquisas com ênfase na percepção, na área de estudo da presente pesquisa destacam-se os autores Silva (2009) e Aires (2012).

A primeira, Silva (2009), realizou uma análise da imagem que turistas e comunidade local têm da Área de Proteção Ambiental dos Recifes de Corais Aparc (RN), especificamente na comunidade de Maracajaú. Esse estudo mostrou a percepção da comunidade e do turista sobre a atividade turística, feito isso muitas informações pertinentes foram identificadas, as quais poderão auxiliar a gestão nas tomadas de decisões sobre a unidade de conservação. Isso visando a um 
planejamento que assegure a manutenção do meio, como também garanta o desenvolvimento sustentável do turismo, dando possibilidade da comunidade ser inserida na atividade.

A segunda, Aires (2012), buscou investigar as possibilidades da isenção da comunidade de Perobas na atividade turística. Para isso, foi necessário conhecer a percepção da comunidade quanto ao desenvolvimento do turismo no local. Feito isso, foi possível analisar os anseios dos moradores, suas opiniões de satisfação e de descontentamento com a atividade turística.

Por fim, é possível afirmar e concordar com o pensamento de Carvalho (2010, p.472) quando diz que conhecer a percepção dos moradores sobre o turismo é necessário para compreender como eles veem a atividade, e como estão inseridos na mesma. Como também essa teoria vale para a percepção dos turistas, pois feito isso será identificado suas satisfações e as não satisfações, essas informações serão pertinentes para auxiliar no planejamento turístico da área. Diante disso, o presente estudo tem como objetivo avaliar a percepção da comunidade com relação ao desenvolvimento do turismo nos recifes de corais de Perobas. Comunidade situada no município de Touros (RN), distante aproximadamente $90 \mathrm{~km}$ da Capital do Estado, Natal.

O parracho de Perobas faz parte da Área de Proteção Ambiental dos Recifes de Corais, juntamente com os parrachos de Maracajaú e Cioba. Essa UC tem como objetivo proteger a região marinha que abrange a faixa costeira dos municípios de Maxaranguape, Rio do Fogo e Touros, no litoral sul do estado. Face às suas belezas naturais e diversidade biológica, a APARC constitui-se como destino turístico do $\mathrm{RN}$, permitindo a prática do mergulho submarino, visitação aos bancos de corais, pesca artesanal e pesquisas científicas (IDEMA, 2013).

Nesse local, as principais atividades econômicas desenvolvidas são 0 turismo e a pesca. Aquela ainda se encontra em fase incipiente, e esta é bastante presente na comunidade, porém os pescadores estão se organizando para se inserir na atividade turística como uma alternativa para ganhos econômicos. Desta forma, o local merece um cuidado especial quanto ao planejamento ambiental e a regulamentação dos usos dos recifes de corais visando à conservação e ao uso racional.

\section{Área de Proteção Ambiental dos Recifes de Corais}

A Área de Proteção Ambiental dos Recifes de Corais, onde se localiza a comunidade de Perobas, foi criada através do Decreto estadual $n^{\circ} 15.476$, de 6 de junho de 2001, sua área é de 32500ha. Ela engloba três parrachos (nome dados aos recifes de corais pela comunidade): Cioba, Maracajaú e Rio do Fogo; e está localizada na plataforma rasa adjacente aos municípios de Rio do Fogo, Touros e Maxaranguape (Figura 1) (AMARAL, et al., 2005). 


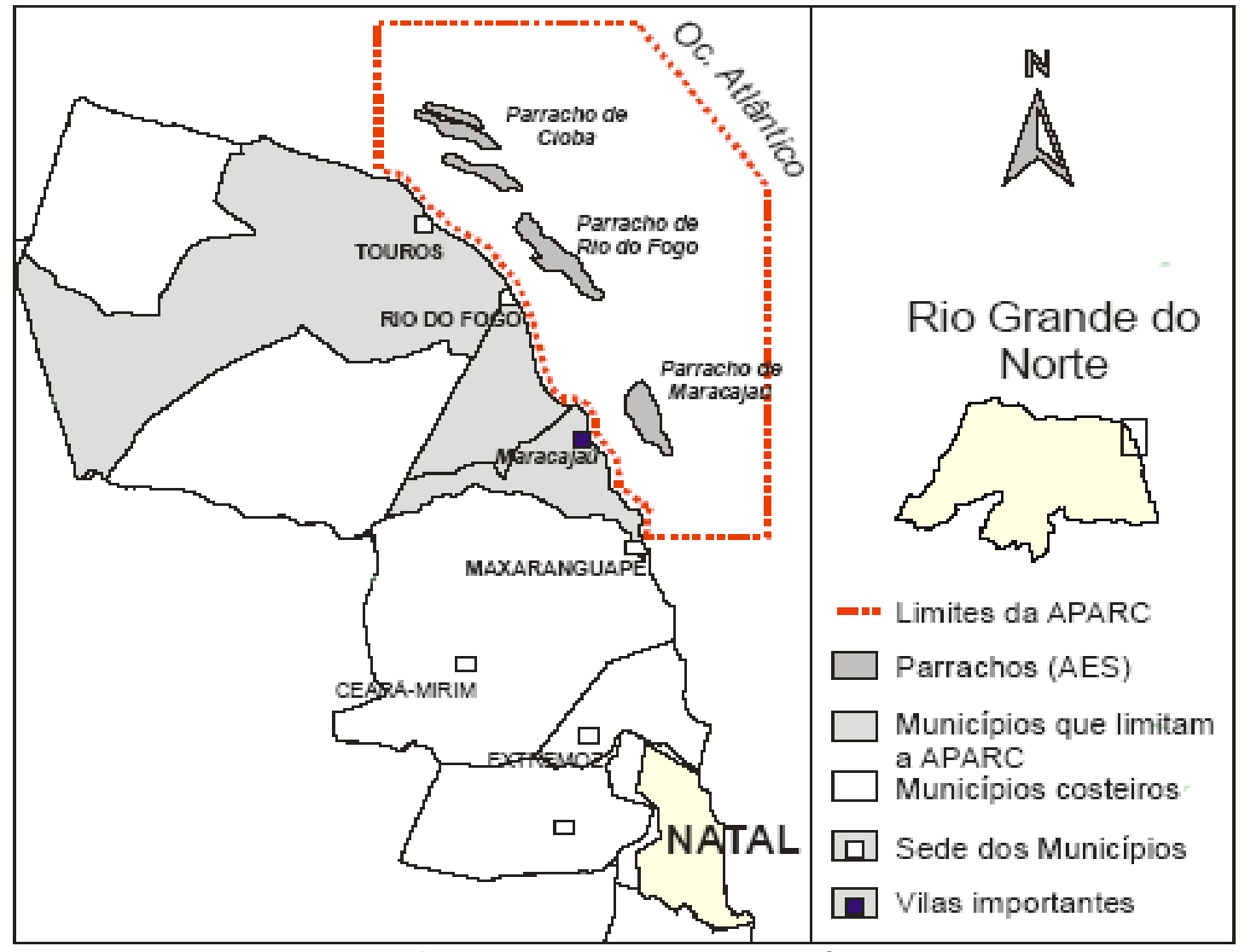

Figura 1: Localização da APARC.

Figure 1: Location APARC.

Fonte: Amaral et al. (2013).

Source: Amaral et al. (2013).

Os objetivos da criação da APARC foram: proteger a biodiversidade e a vida marinha presentes na área com ocorrência de recifes de corais e suas adjacências; controlar e normatizar as práticas de ecoturismo comercial, do mergulho e da pesca local; desenvolver na comunidade, nos empreendedores e visitantes uma consciência ecológica e conservacionista sobre o patrimônio natural e os recursos ambientais marinhos; incentivar a utilização de equipamentos de pesca artesanal ecologicamente corretos e incentivar a realização de pesquisas para a identificação e o comportamento dos organismos marinhos visando propiciar um maior conhecimento do ecossistema (RIO GRANDE DO NORTE, 2001).

\section{A comunidade de Perobas e o Parracho de Rio do Fogo}

A comunidade de Perobas faz o uso do parracho por meio da atividade turística. Ela está localizada no município de Touros/RN, distante de aproximadamente $90 \mathrm{~km}$ da Capital do Estado, Natal o qual, juntamente com os municípios de Maxaranguape e Rio do Fogo, faz parte da área de influência direta da Área de Proteção Ambiental dos Recifes de Corais (ver na figura 2).

Já o parracho de Rio do Fogo apresenta uma formação recifal, próximo à sede municipal, sendo conhecido localmente por "Parracho de Rio do Fogo". A extensão total dos recifes dessa região é de $11,72 \mathrm{~km}^{2}$. Atualmente o maior uso é das atividades pesqueiras, e apenas há a visitação informal da própria comunidade. 
Visando estabelecer o ordenamento das atividades foram definidas as zonas, nas quais se inclui a de uso turístico e de lazer.

Visando ordenar a área antes do início de atividades mais intensivas de turismo recreativo, o plano de manejo estabelece uma zona de 0,63 km2 (63,22 ha), que abrange $5 \%$ do total da área continental. O tamanho é relativamente reduzido, mas foi determinado devido à necessidade da preservação do ecossistema altamente rico, e a fim de conciliar com a atividade pesqueira que ainda é a principal fonte econômica para a região (IDEMA, 2011).

De acordo com o plano de manejo, foi decidido que para o parracho de Rio do Fogo seria destinado 100 cotas para realização dos passeios. No entanto, foi feito um acordo que entre as comunidades, no qual ficou estabelecido que Perobas também faria o uso do parracho, de maneira que foi destinado 100 cotas também para a comunidade (50\% para pescadores e $50 \%$ para empresas).

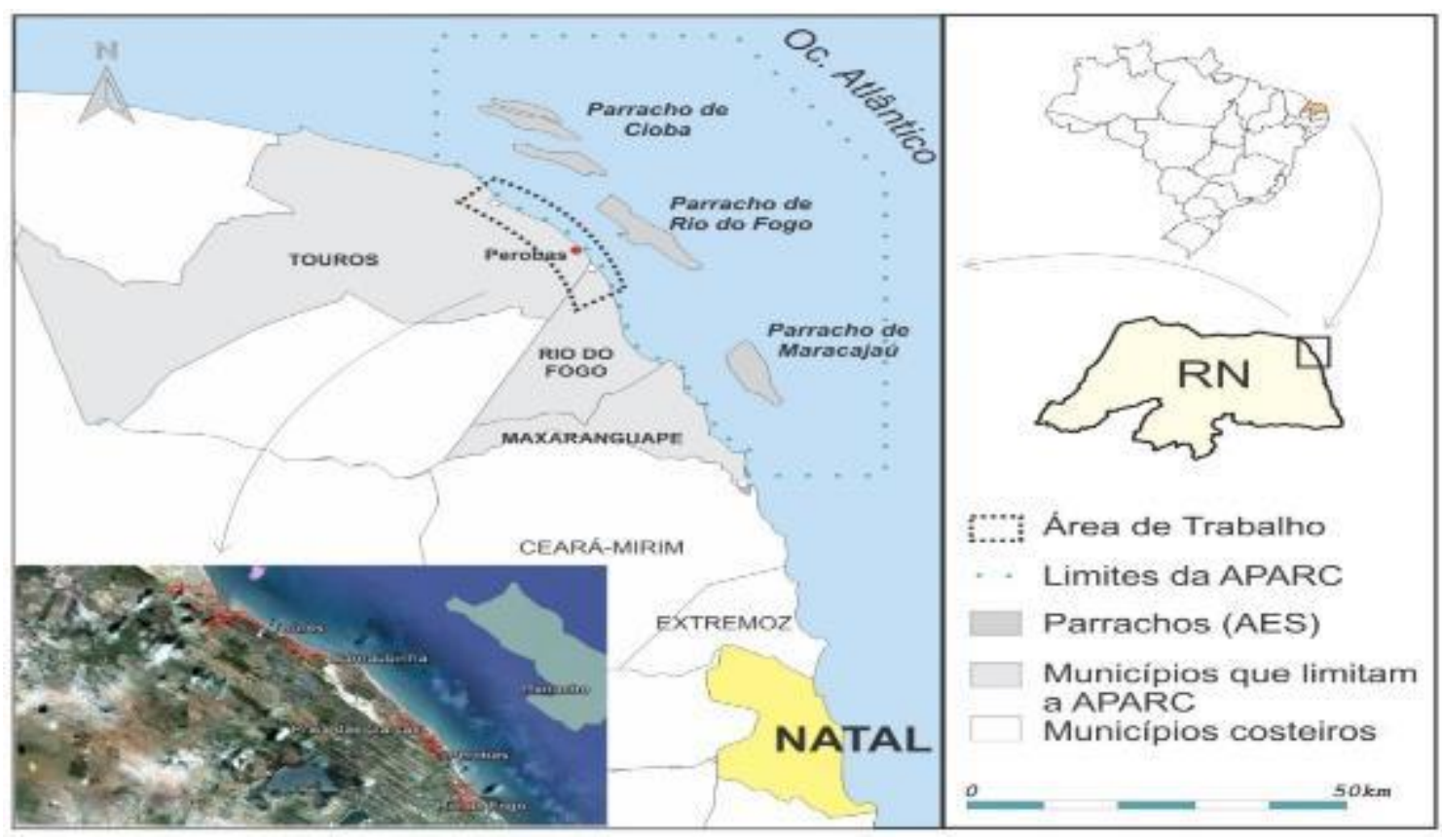

Figura 2: Localização da comunidade de Perobas.

Figure 2: Location of community Perobas.

Fonte: Amaral et al. (2013).

Source: Amaral et al. (2013)

\section{Metodologia}

O presente estudo caracteriza-se como exploratório e esta pesquisa adotou uma abordagem quali-quantitativa. Para realização da pesquisa 0 universo considerado foi à comunidade de Perobas; com relação à amostra, os números de entrevistados foram escolhidos de acordo com a conveniência do pesquisador. Esse método justifica-se pelo fato de não acesso aos dados precisos dos habitantes da comunidade e da quantidade de turistas que fazem os passeios nos recifes de corais (DENCKER, 1998). Desse modo, foram aplicados 60 formulários, que equivale a $15 \%$ da população de aproximadamente 400 habitantes, dos quais 59 foram válidos. Já o instrumento de pesquisa foi composto por perguntas fechadas, abertas e multiescolha, e foi divido também em três partes: a) dados pessoais, b) 
importância do parracho para a comunidade e c) percepção sobre o turismo. 0 formulário foi o utilizado no estudo de Silva (2009).

Como método de observação foi realizado um passeio aos parrachos com turistas para verificar in loco a logística e a dinâmica do passeio, na oportunidade foi feito a captura de imagens, como também conversas informais com os responsáveis pelas embarcações.

A aplicação dos formulários foi realizada no período que compreende de 9 a 13 de Janeiro de 2014, com o auxílio de quatro aplicadores (incluindo o pesquisador), distribuídos em quatro principais setores da comunidade, como pode ser visto na figura 1: o aplicador 1 ficou na área mais próxima da praia, o aplicador 2 ficou na rua principal, o aplicador 3 nas últimas ruas e o aplicador 4 ficou nas ruas do início.

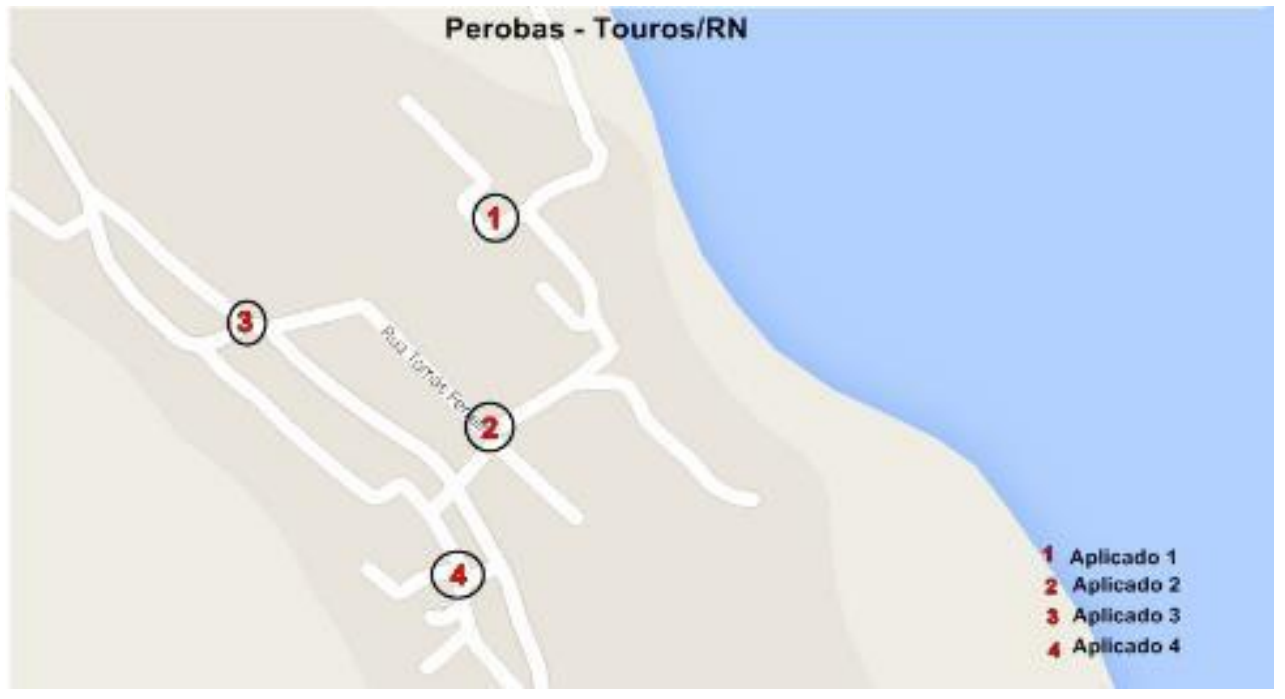

Figura 3: Distribuição dos aplicadores. Fonte: Oliveira (2014).

Figure 3: Distribution of applicators. Source: Oliveira ( 2014).

Após os dados obtidos no campo foi feito a tabulação de forma quantitativa. Assim, as questões semiabertas, fechadas e de múltipla escolha foram analisadas de forma quantitativa, através de análise descritiva (porcentagem, média, frequência). Para as questões abertas foi feito a análise de conteúdo "que consiste em um conjunto de técnicas de análise das comunicações” (BARDIN, 2007, p. 27).

Para a tabulação da análise de conteúdo, incialmente foi feito a codificação das respostas e posteriormente realizado a categorização das respostas em símbolos. Segundo Dencker, (1998, p. 163) isso "é o processo técnico pelo qual são categorizados os dados. Através da codificação os dados brutos são transformados em símbolos [...]".

Por exemplo, para a categoria ajuda a preservar o local, foram agrupadas respostas como "protege o meio ambiente", "manter sempre a proteção" e "ajuda a preservação". Feito isso, foi calculado a frequência das repostas. Logo, foi possível ter exatidão da quantidade de vezes que cada símbolo (e seus sinônimos) aparecia.

Por fim, os dados foram tabulados e analisados com o apoio software estatístico Statistical Package for the Social Sciences (SPSS® 12.0). 


\section{Resultados e discussões}

O perfil dos entrevistados está representado na Tabela 1. Quanto ao gênero $64 \%$ correspondem ao feminino, enquanto $36 \%$ ao masculino. Com relação à faixa etária observa-se que $51 \%$ se enquadram de 31 aos 50 anos, tendo como a média de idade dos moradores 34 anos. No tocante ao estado civil, destacam-se os casados e os solteiros, $51 \%$ e $39 \%$ respectivamente.

Ao se tratar do grau de escolaridade observa-se que a maioria dos moradores tem o ensino fundamental incompleto (34\%), enquanto 3\% possui ensino superior completo. Com relação à profissão $34 \%$ dos moradores trabalham diretamente com o mar (17\% pescador, 17\% marisqueira).

No tocante à renda familiar, $41 \%$ das famílias possuem renda acima de $R \$$ $1.000,00$, seguido de $34 \%$ menos de 1 salário mínimo, $12 \%$ com 1 salário mínimo, $10 \%$ têm salário entre $R \$ 800,00$ a $R \$ 1.000,00$ e 3\% não souberam informar. No tocante à religião, $88 \%$ disseram ser católicos, $5 \%$ protestantes, $3 \%$ outra religião, $2 \%$ sem religião e $2 \%$ não respondeu.

Tabela 1: Perfil dos moradores da comunidade de Perobas.

Table 1: Profile of the residents of Perobas community.

\begin{tabular}{|c|c|c|c|}
\hline & & $f$ & $\%$ \\
\hline \multirow{2}{*}{ Gênero } & Masculino & 21 & 36 \\
\hline & Feminino & 38 & 64 \\
\hline \multicolumn{2}{|l|}{ TOTAL } & 59 & 100 \\
\hline \multirow{4}{*}{ Estado Civil } & Casado & 30 & 51 \\
\hline & Solteiro & 25 & 39 \\
\hline & Separado/Desquitado & 4 & 7 \\
\hline & Viúvo & 2 & 3 \\
\hline \multicolumn{2}{|l|}{ TOTAL } & 61 & 100 \\
\hline \multirow{5}{*}{ Renda Familiar } & Menos de 1 salário mínimo & 20 & 34 \\
\hline & 1 salário mínimo & 7 & 12 \\
\hline & Entre $R \$ 8.00$ e $R \$ 1.000$ & 6 & 10 \\
\hline & Acima de $R \$ 1.000$ & 24 & 41 \\
\hline & Não sabe & 2 & 3 \\
\hline \multicolumn{2}{|l|}{ TOTAL } & 59 & 100 \\
\hline \multirow{9}{*}{ Profissão/Ocupação } & Funcionário público & 13 & 20 \\
\hline & Pescador & 10 & 14 \\
\hline & Estudante & 10 & 14 \\
\hline & Marisqueira & 10 & 14 \\
\hline & Doméstica/Dona de casa & 8 & 12 \\
\hline & Autônomo & 8 & 12 \\
\hline & Aposentados & 3 & 4 \\
\hline & Comerciantes & 3 & 4 \\
\hline & Outros & 4 & 6 \\
\hline \multicolumn{2}{|l|}{ TOTAL } & 69 & 100 \\
\hline \multirow{6}{*}{ Escolaridade } & Ensino fundamental incompleto & 20 & 43 \\
\hline & Ensino fundamental completo & 10 & 21 \\
\hline & Ensino médio incompleto & 8 & 17 \\
\hline & Ensino médio completo & 6 & 13 \\
\hline & Ensino superior incompleto & 1 & 2 \\
\hline & Ensino superior completo & 2 & 4 \\
\hline \multicolumn{2}{|l|}{ TOTAL } & 47 & 100 \\
\hline \multirow{4}{*}{ Religião } & Católico & 51 & 89 \\
\hline & Protestante & 3 & 5 \\
\hline & Sem religião & 1 & 2 \\
\hline & Outra & 2 & 4 \\
\hline \multicolumn{2}{|l|}{ TOTAL } & 57 & 100 \\
\hline
\end{tabular}


Quando perguntado aos moradores sobre a importância do parracho, 100\% responderam ser importante, isso mostra que os recifes de corais possuem valor considerável para a comunidade de Perobas. Como também é o principal atrativo turístico da comunidade, pensamento esse que ainda persiste na comunidade, pois também foi observado na pesquisa de Aires (2012). Ou seja, os parrachos ainda são o ponto de identidade/importância dos moradores.

As respostas que justificaram a importância foram agrupadas em cinco categorias, a saber: Turismo, Pesca, Sobrevivência da Comunidade, Beleza Natural, Emprego e Renda. Houve também os que não souberam responder ou que deram respostas que não se enquadram em nenhuma destas categorias.

Neste caso, 39\% dos entrevistados justificaram que o parracho é importante porque desenvolve o turismo (categoria Turismo), enquanto, 18,6\% falaram que significa a sobrevivência da comunidade (categoria Pesca), 11,9\% deram respostas que foram agrupadas em Beleza Natural, 10,2\% disseram que seria por causa da pesca artesanal e por fim $6,8 \%$ disseram que seria importante por ser uma fonte de geração de emprego e renda, e 3,4\% não souberam responder, e 10,2\% deram outras respostas, como mostra o Gráfico 1 a seguir.

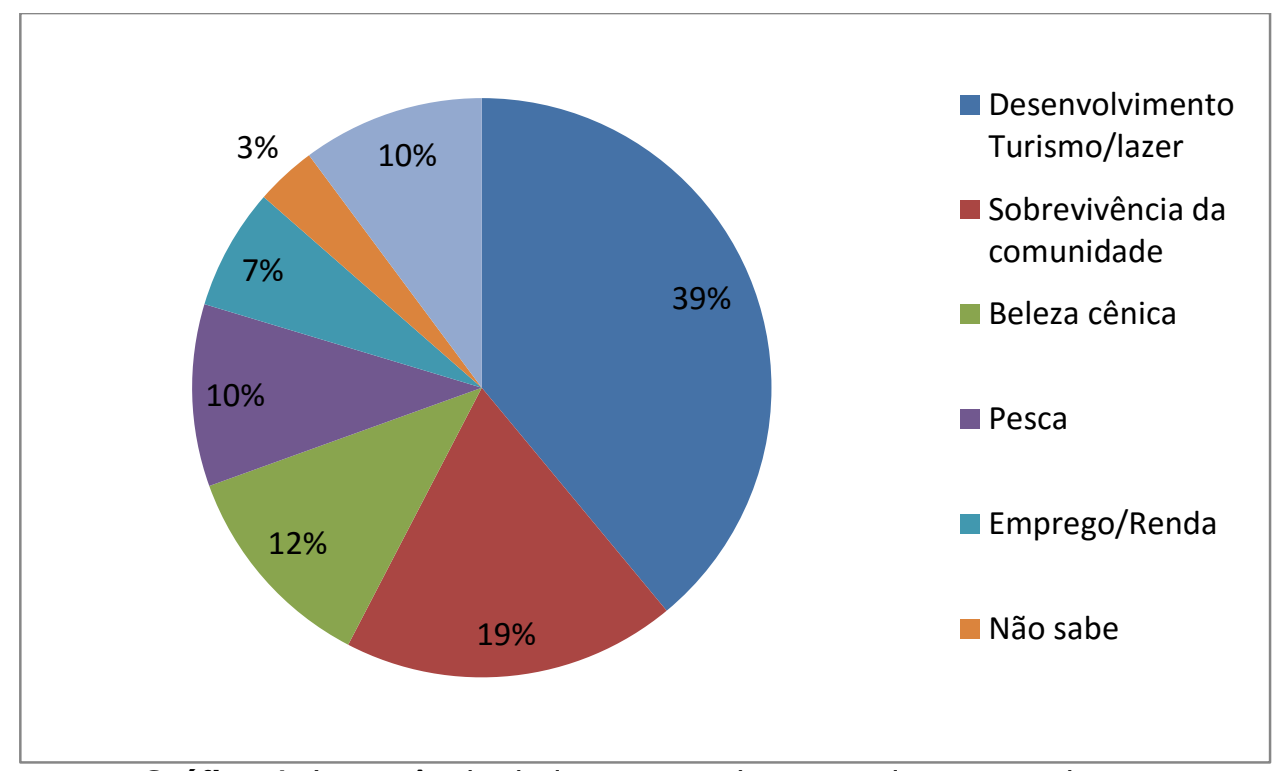

Gráfico 1: Importância dada ao parracho segundo os moradores. Graph 1: Importance given to the brill according to residents.

Fonte: Dados da pesquisa (2014).

Source: Survey data (2014).

A categoria Desenvolvimento turismo/lazer, na qual foi a mais citada (39\%), reuniu respostas que deram ideia que o parracho tem uso exclusivamente para 0 turismo, tipo: "porque lá é uma reserva, e também é uma atração turística", e "por que atrai turista".

A segunda categoria mais citada foi a de Sobrevivência da Comunidade $(18,6 \%)$, congrega respostas que apontam o parracho como principal meio de sobrevivência da comunidade, e que muitos se beneficiam por meio do uso do local, seja através da pesa ou do turismo. Exemplos de repostas: "traz benefícios para a comunidade", "[...] é o meio de sobrevivência da comunidade" e "porque muitos sobrevivem de lá". 
$\mathrm{Na}$ categoria Beleza Cênica, a terceira com (12\%), foram agrupadas respostas que indicam um local possuído por beleza, como "tem muita coisa bonita", "por que tem muita coisa linda", "por que é bonito".

Enquanto a quarta categoria Pesca, a quarta mais cogitada pelos entrevistados (10\%), concentrou respostas em que as pessoas citavam que o local é um lugar que desenvolve a atividade da pesca e que considerável parte da comunidade sobrevive desta, como é o caso de um entrevistado J. M. de 52 anos, casado, que disse "é uma fonte de renda e alimentação para os pescadores".

A categoria emprego, a quinta com (7\%), reuniu respostas ligadas a trabalho, colocando que o parracho é um meio de geração de emprego e renda para a comunidade, a entrevistada W. A., de 19 anos, casada, falou que o local é importante porque "traz turismo para o município e é um meio de renda".

Quando perguntado o que o parracho significa ou representa, obteve-se o seguinte resultado (Gráfico 2): 22\% responderam ser o meio de sobrevivência, 20 $\%$ disseram que significa muito sem retratar motivo específico, $20 \%$ representa um monumento natural pertencente à comunidade, 19\% representa beleza natural, $14 \%$ representa atividade turística, $3 \%$ não souberam responder e $2 \%$ disseram significar pouco.

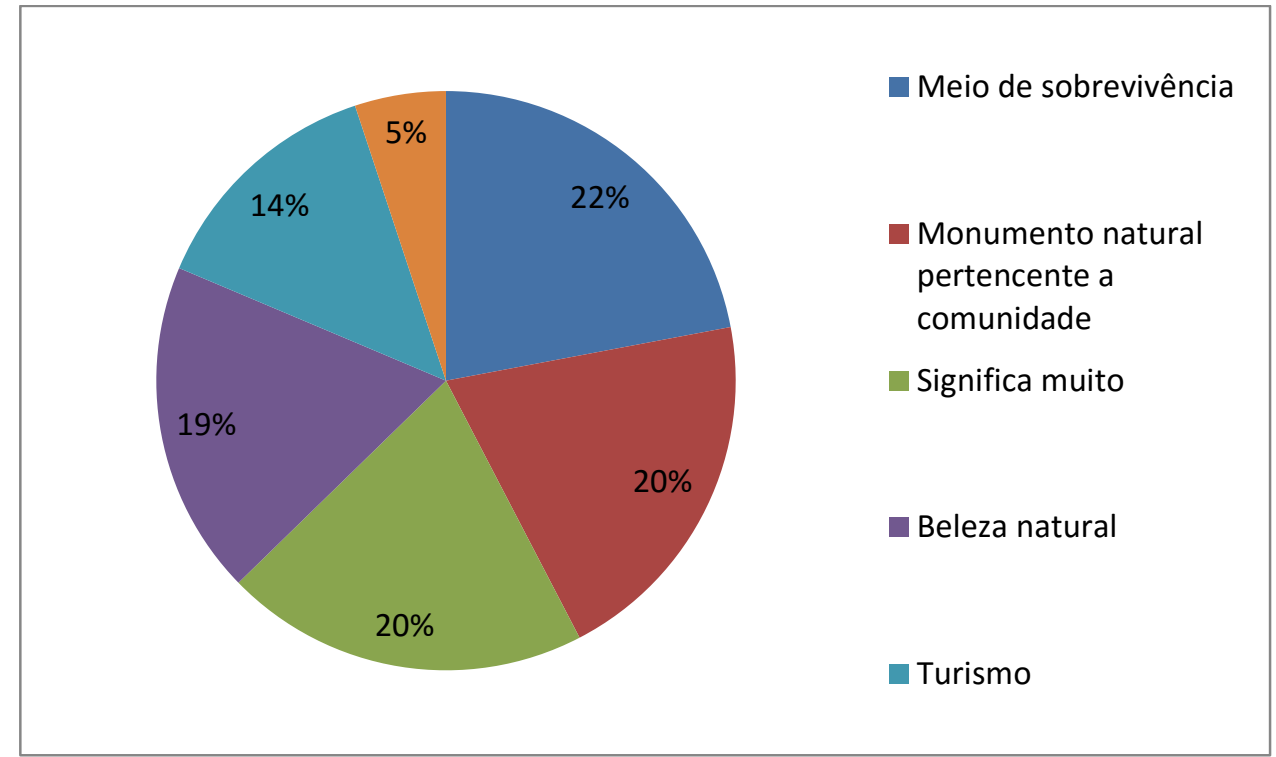

Gráfico 2: Significado atribuído ao parracho pelos moradores de Perobas. Graph 1: Meaning attributed to Brill by residents of Perobas.

Fonte: Dados da pesquisa (2014).

Source: Survey data (2014).

A categoria significa muito, Meio de Sobrevivência, apresenta respostas como "lugar de trabalho", "é uma coisa muito boa, porque da a sobrevivência"; a categoria Monumento natural pertencente à comunidade reuniu respostas como "um lugar muito importante para a comunidade" e "um monumento cultural, uma coisa muito importante"; a categoria significa muito concentrou respostas como "significa muito", "muito importante", "tudo"; a categoria Beleza natural compreende respostas que ressaltam a beleza cênica, "um local de beleza natura" e "representa beleza"; a categoria Turismo expressa respostas como "ponto de turismo", "um lugar atrativo"; a categoria Não sabe reuniu respostas como "não sabe", "não sei"; e a categoria Significa pouco tem apenas uma resposta que dizia "significa pouco". 
Em seguida foi questionado se os moradores sabiam o que é uma Área de Proteção de Ambiental, pouco mais da maioria dos entrevistados disseram que não sabia $57,6 \%$. Enquanto $42,4 \%$ disseram saber, relacionando a APA em três categorias, que são: área protegida $67 \%$; proteção do parracho $25 \%$; um local que não pode jogar lixo 8\%, como pode ver no Gráfico 3.

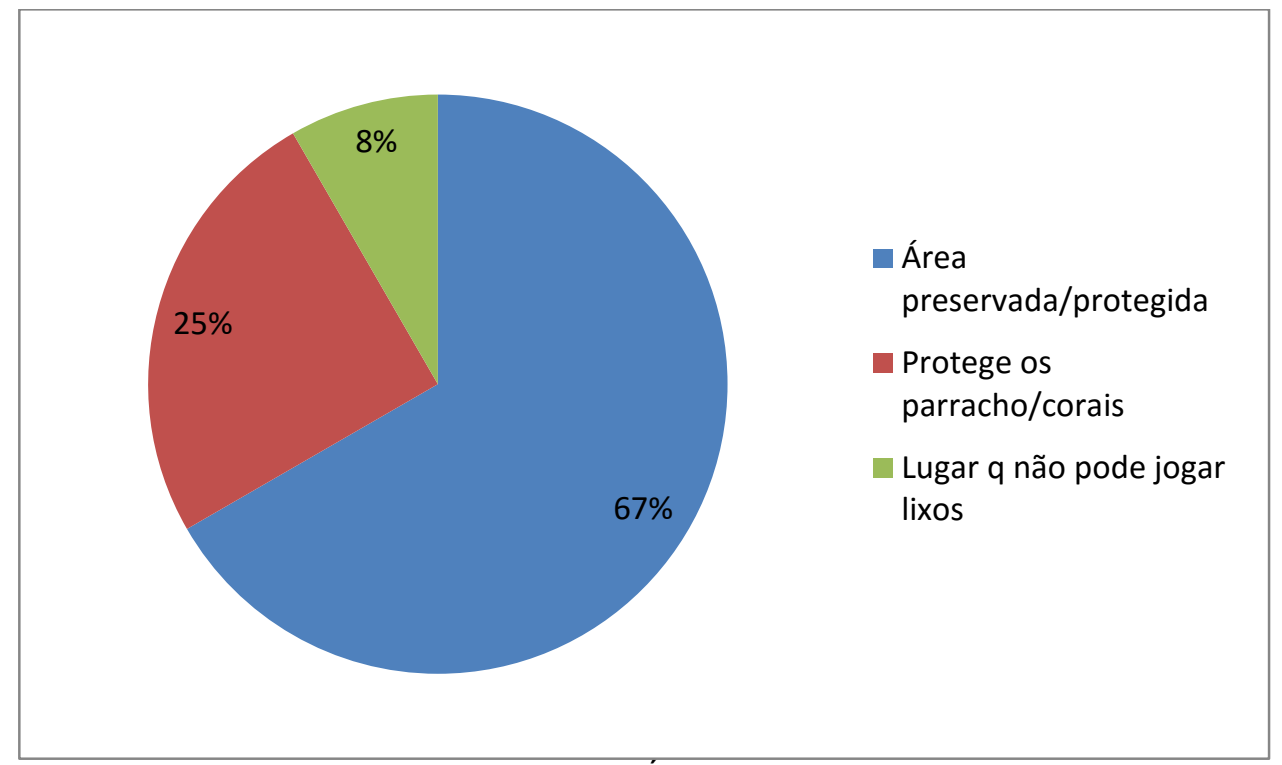

Gráfico 3: O que seria uma Área de Proteção Ambiental. Graph 3: What would be an Environmental Protection Area.

Fonte: Dados da pesquisa (2014).

Source: Survey data (2014).

Ainda foi questionado se os moradores sabiam que os recifes de corais fazem parte de uma Área de Preservação Ambiental, a maioria 83,1\% disse que sim e apenas 16,9\% disseram não. Esse dado demostra ser significativo uma vez que considerável parte da comunidade sabe que o parracho faz parte de uma área protegida, que a localidade está inserida numa APA, então a comunidade é consciente que no local existe regras para conservação e que os moradores se tornam um potencial agente fiscalizador, podendo verificar se os usos que estão sendo feitos estão adequados ou não.

E quando questionado sobre a importância do parracho pertencer a uma APA, $98,2 \%$ disseram ser importante, isso mostra que a comunidade tem conhecimento que aquele local além de poder desenvolver suas atividades, também é uma ferramenta que provem benefícios em termos biológicos e ambientais, pois um dos principais benefícios que uma UC pode gerar é guardar e proteger ecossistemas naturais que são essências na manutenção dos sistemas sustentadores de vida.

Após justificaram essa importância dada à área dos recifes de corais, as repostas foram reunidas em seis categorias: Ajuda a preservar/conservar o meio ambiente; Ajuda a proteger os corais/parracho/peixes; Garante a continuidade do turismo/pesca; Proibi jogar lixo; Por pertencer a comunidade; e Não responderam/não sabe, como pode ver na Tabela 2 a seguir. 


\begin{tabular}{|l|l|c|c|}
\hline \multicolumn{3}{|c|}{$\begin{array}{l}\text { Tabela 2: Justificativas da importância atribuída ao parracho pelos moradores de Perobas. } \\
\text { Table 2: Justifications of the importance attributed to the brill by the residents of Perobas. }\end{array}$} \\
\hline \multicolumn{1}{|c|}{ Categorias } & \multicolumn{1}{|c|}{ Sentido das respostas } & f & $\%$ \\
\hline $\begin{array}{l}\text { Ajuda a Preservar/conservar } \\
\text { o Meio Ambiente }\end{array}$ & $\begin{array}{l}\text { Preservação, conservação do meio } \\
\text { ambiente }\end{array}$ & 25 & 42,4 \\
\hline $\begin{array}{l}\text { Ajuda a proteger os } \\
\text { corais/parrachos/peixes }\end{array}$ & Preservação da vida marinha do local & 10 & 16,9 \\
\hline $\begin{array}{l}\text { Garante a continuidade do } \\
\text { turismo/pesca }\end{array}$ & $\begin{array}{l}\text { Durabilidade da atividade de turismo e } \\
\text { pesca }\end{array}$ & 7 & 11,9 \\
\hline \begin{tabular}{l} 
Proibi jogar lixo \\
\hline Por pertencer a comunidade
\end{tabular} & $\begin{array}{l}\text { Nonumento natural que pertence a } \\
\text { comunidade }\end{array}$ & 7 & 11,9 \\
\hline $\begin{array}{l}\text { Não responderam/não sabe } \\
\text { TOTAL }\end{array}$ & $\begin{array}{l}\text { Pessoas que não quiseram ou não sabiam } \\
\text { responder }\end{array}$ & 2 & 3,4 \\
\hline $\begin{array}{l}\text { Fonte: Dados da pesquisa (2014). } \\
\text { Source: Survey data (2014). }\end{array}$ & $\mathbf{5 3}$ & 100 \\
\hline
\end{tabular}

Com esse resultado, percebe-se que as principais justificativas estão ligadas a preservação e conservação do local, que são as primeiras duas categorias, a terceira está atrelada a importância de garantir as atividades econômicas de onde provêm o sustento daquela comunidade, devam garantir a continuidade das atividades e que as futuras gerações possam ter acesso aquele recurso natural, no qual a comunidade possui um pertencimento que foi visível em considerável parte dos questionamentos.

Além disso, foi possível verificar que $81,4 \%$ dos entrevistados frequenta 0 parracho, sendo que $31,3 \%$ frequenta raramente, $22,9 \%$ às vezes, $18,8 \%$ algumas vezes e $27,1 \%$ muitas vezes. No gráfico 4 a seguir mostrará os usos. Os principais usos que os moradores fazem é tomar banho, diversão e lazer, 31,3\% e 20,8\% respectivamente, 20,8\% para pesca, 14,6 \% mergulho e 4,2\% levar os turistas, 8,3\% (Gráfico 4).

Após essa análise, é possível ver que a comunidade utiliza o local não apenas para desenvolver alguma atividade econômica, mas também para lazer e diversão, isso é importante uma vez que o recurso natural não é restringido apenas para os turistas, a própria comunidade faz diversos usos, porém deve existir uma preocupação de utilizar de forma adequada evitando ao máximo que ocorra algum impacto.

Todavia, como nem todos frequentam o local (19\%), considerável parte justificou dizendo que tem medo (45,5\%), onde 18,2\% não tem interesse, e as respostas como falta de tempo, questão financeira, não teve oportunidade e não sabe obtiveram a mesma percentagem $9,1 \%$.

Ainda foi indagado aos moradores se sabiam o que podia e o que não era permitido fazer nos parrachos, então $83 \%$ dos entrevistados disse que sim, destacado que podia pescar, tomar banho e mergulhar. $\mathrm{E}$ o que não era permitido fazer os moradores citou jogar lixo, pegar peixes, levar corais, fazer refeição e fazer passeios sem segurança (coletes). 


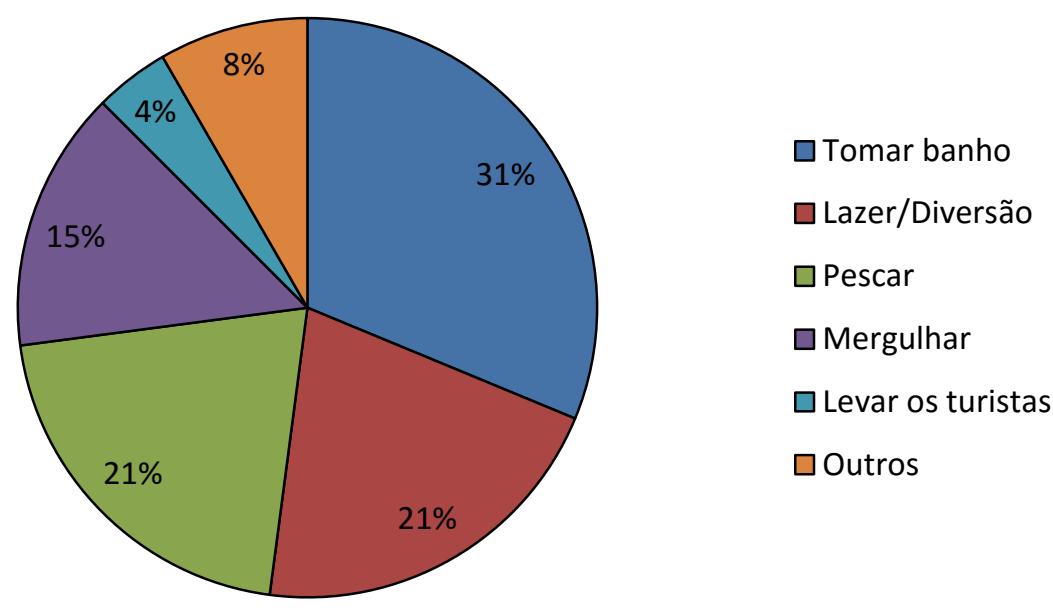

Gráfico 4: Os usos do parracho pelos moradores.

Graph 4: The Brill uses by residentes.

Fonte: Dados da pesquisa (2014).

Source: Survey data (2014).

Um dos principais aspectos analisados nesta pesquisa foi saber qual a percepção da comunidade quando ao desenvolvimento do turismo em sua localidade. Também foi perguntado se eles consideravam que o turismo era uma ferramenta de geração de benefícios para a comunidade, sendo assim, 88,1\% disseram que sim, enquanto apenas $11,9 \%$ disseram não trazer benefícios.

Desse modo, percebe que a comunidade vê o turismo como uma atividade positiva, ainda para completar, foram citados pelos moradores quais os benefícios que o turismo pode gerar na comunidade, como pode vê no Gráfico 5.

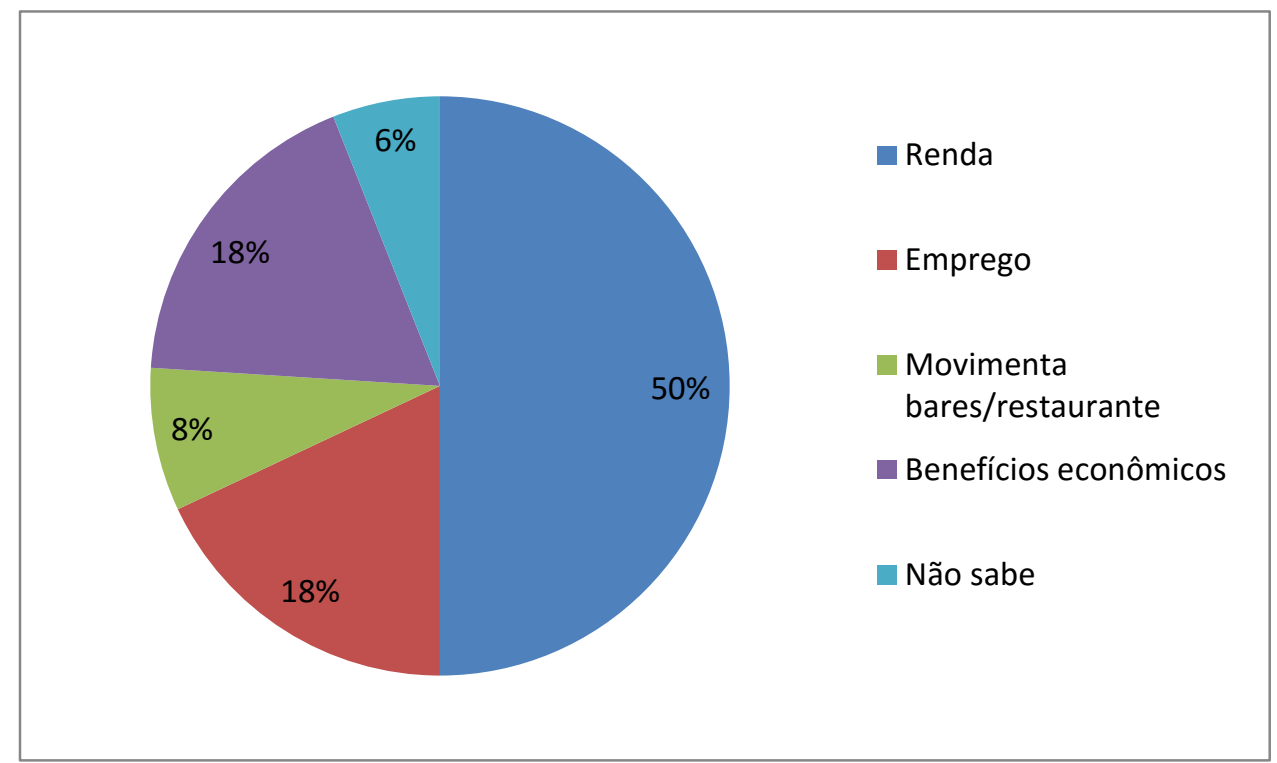

Gráfico 5: Benefícios do turismo para a comunidade.

Graph 5: Benefits of tourism to the community.

Fonte: Dados da pesquisa (2014).

Source: Survey data (2014). 
Diante desse resultado, o que pode observar é que as respostas atribuídas a essa pergunta todas convergem com a geração de ganhos econômicos do turismo para a comunidade, sempre inserida em uma lógica de mercado, fazendo com que os moradores pensem que o turismo é uma atividade apenas com ganhos econômicos, negligenciando os benefícios de conservação dos recursos naturais como também a valorização do território e a da cultural local.

Dos entrevistados $15 \%$ disseram que o turismo traz algo de ruim para a comunidade, citando os motivos, tais como: entrada de drogas, exploração da mão de obra barata, problemas ambientais, aumentos dos preços dos bens, ocupação do espaço da praia, gera confusão entre os pescadores e lixo na praia. Sem nenhuma dúvida esses motivos são coerentes, tendo em vista que o turismo sem as bases do planejamento turístico pode ocorrer vários fatores negativos, podendo levar o destino a estado de declínio. Além disso, pode-se fazer alusão que o turismo deva ser bom tanto para os agentes que estão diretamente relacionados com o turismo, como também para a comunidade residente.

Em seguida, foi questionado aos moradores se o turismo deveria continuar na comunidade, $96,6 \%$ disseram que sim, justificado pelos seguintes motivos: para os turistas visitar/conhecer, fonte de renda, sobrevivência da comunidade e não sabe explicar (Gráfico 6).

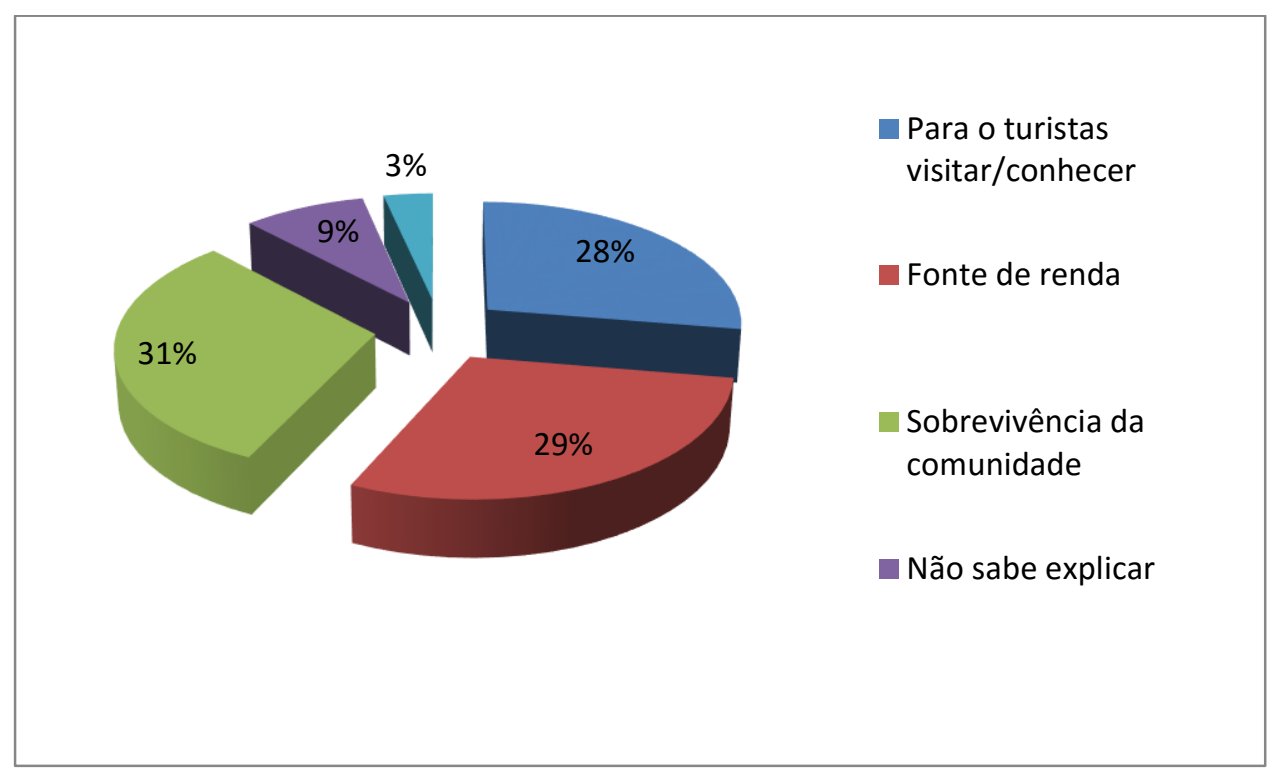

Gráfico 6: Os motivos pelos quais não se deve acabar o turismo. Graph 6: The reasons why one should not end tourism.

Fonte: Dados da pesquisa (2014).

Source: Survey data (2014).

Como foi possível observar, o principal motivo que justifica que o turismo não deve acabar visto que é considerado um meio gerador de renda. Pessoa e Rabinovici (2010) afirmam que o incremento da renda do turismo é distribuído para todos, têm os que estão inseridos e outros por não estarem aptos não estão envolvidos na atividade turística. Desse modo, os autores afirmam que pode resultar em grave problema especialmente quando a atividade oferece condições diferenciadas de acesso ao emprego e renda, criando novas desigualdades e conflitos. 
Complementando essa discussão, foi indagada qual a opinião da comunidade quanto aos empresários do turismo, considerável parte dos moradores opinou a favor dos empresários, justificando que eles estavam trazendo benefícios para a comunidade por meio da geração de empregos para os moradores e são pessoas que colaboram para o desenvolvimento do turismo na comunidade. Exemplo de respostas como, "traz turistas para a comunidade", "dá emprego aos jovens nas embarcações" e "traz benefícios para a comunidade".

Porém, existe os moradores não favoráveis, na qual ressaltaram não estarem satisfeitos com as conduta, exemplos de respostas, "[...] eles deveriam ouvir mais a população sobre tomada de decisão", "São exploradores", "Eles não procuram ajudar a comunidade"

Diante disso, é preciso ser feito um planejamento visando minimizar os impactos negativos, sobretudo os conflitos gerados ente os que querem e os são contra o desenvolvimento do turismo. Segundo Salvati (2003, p.51), o "descontentamento da população provoca um ambiente hostil ao turismo, diminuindo a qualidade da 'atmosfera' e, portanto, podendo causar redução do fluxo de turistas". Pessoa e Rabinovici (2010) ressaltam que sempre os conflitos são sinônimos de problemas, mas o mesmo levam a medidas de precauções e preocupações quanto a um planejamento responsável, e à minimização dos impactos sociais.

Logo ao ser perguntado a comunidade qual o item que precisava ser melhorado, tiveram as seguintes respostas (Tabela 3):

Tabela 3: Itens que precisam ser melhorados na comunidade de Perobas.

Table 3: Items that need to be improved in the community Perobas

\begin{tabular}{|c|c|c|c|}
\hline & & $f$ & $\%$ \\
\hline \multirow{11}{*}{ Itens a serem melhorados } & Estradas/Sinalização & 10 & 17 \\
\hline & $\begin{array}{l}\text { Aumentar de números de } \\
\text { passeios }\end{array}$ & 9 & 15 \\
\hline & Diminuir o preço dos passeios & 2 & 3 \\
\hline & Número maior de pousadas & 2 & 3 \\
\hline & Incentivo do poder público & 5 & 9 \\
\hline & Conservar/Preservar & 2 & 3 \\
\hline & Limpeza da comunidade & 4 & 7 \\
\hline & $\begin{array}{l}\text { Organização/União entre } \\
\text { empresários e nativos }\end{array}$ & 6 & 10 \\
\hline & $\begin{array}{l}\text { Inserir a comunidade na } \\
\text { cadeia produtiva do turismo }\end{array}$ & 6 & 10 \\
\hline & Precisar melhorar nada & 5 & 9 \\
\hline & Não sabe & 8 & 14 \\
\hline \multicolumn{2}{|l|}{ TOTAL } & 59 & 100 \\
\hline
\end{tabular}

Fonte: Dados da pesquisa (2014).

Source: Survey data (2014). 
Diante disso, o item mais foi evidenciado para ser melhorado foi relacionado com o acesso ao destino (estradas/sinalização), foi possível constatar in loco que o acesso é uma estrada de chão batido, o que está diretamente ligado ao desenvolvimento do turismo, visto que o acesso é o principal meio junto com o transporte para se deslocar até o destino turístico. Na pesquisa feita em 2012 por Aires, o acesso também foi apontado como principal motivo a ser melhorado, já se passaram dois anos e o problema continua sem nenhuma previsão a ser resolvido.

Assim, sugere-se que exista uma gestão participativa onde a comunidade local possa ter voz e reivindique melhorias para o benefício da população. Pessoa e Rabinovici (2010, p.112), afirma que a "participação comunitária no planejamento não consiste apenas receber passivamente os benéficos da atividade turística, mas sim intervir na sua condução, planejamento e implantação". Nesse sentido pode-se afirmar que a gestão participativa é considerada um importante instrumento de planejamento e manejo que visa minimizar os impactos tanto da unidade como nas comunidades residentes do entorno.

Por último, foi pedido que os entrevistados atribuíssem uma nota à forma como o turismo está sendo desenvolvido no parracho, apesar de terem apontado alguns aspectos a serem melhorados, grande parte dos entrevistados mostraram estarem satisfeito, (27,1\%) atribuíram nota 8 e (30,5\%) atribuíram nota 10. E 39\% apontaram nota entre 3 e 7 , e apenas 3,4\% atribuíram nota entre 1 e 2 .

Foi perguntado quantas pessoas morava com os entrevistados, e $35,6 \%$ das famílias são compostas por 4 pessoas, e 16,9\% por 3 pessoas, esses foram os principais resultados, tendo apenas uma pessoa morando só. Em seguida foram questionadas quantas pessoas trabalhavam e resultado obtido ficou em entre 1 ou 2 pessoas que trabalhavam.

Além disso, das pessoas que moravam com os entrevistados, $45,8 \%$ pelo menos uma pessoa desenvolvia algum trabalho relacionado com o turismo. Dado o resultado, o que se verifica que $64 \%$ das funções que as pessoas desenvolvem estão diretamente ligadas aos passeios aos recifes de corais, sendo que essas também exercem a atividade da pesca paralelamente (Gráfico 7).

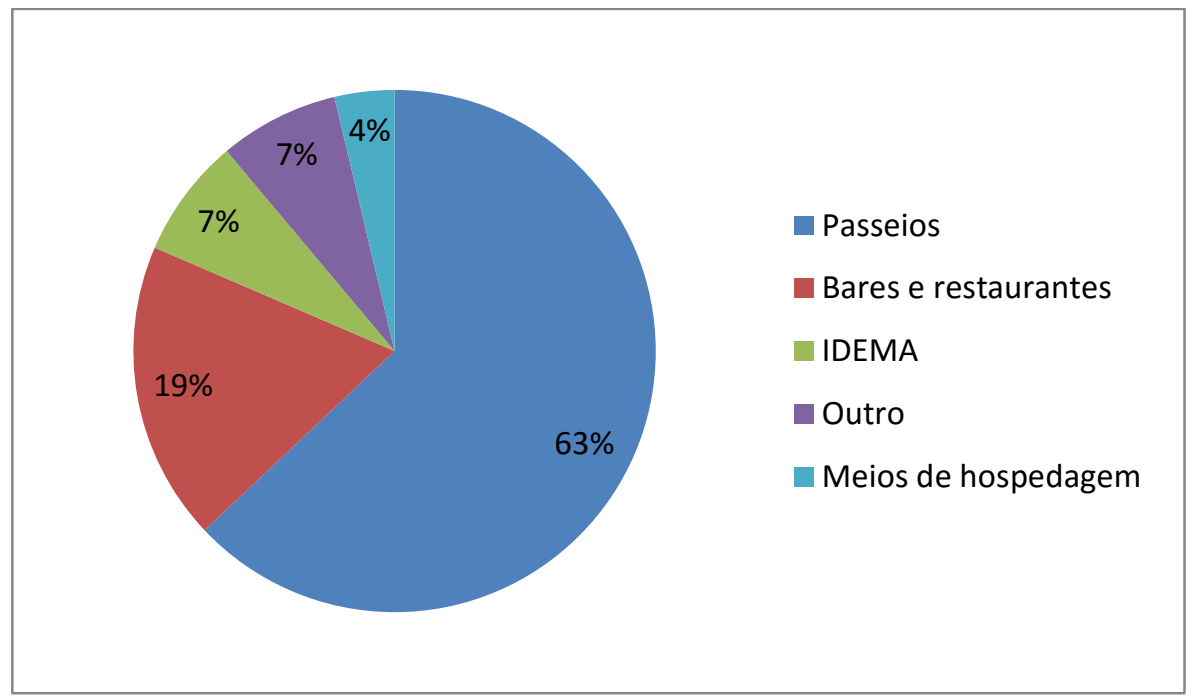

Gráfico 7: Setores de trabalho.

Graph 7: Work sectors.

Fonte: Dados da pesquisa (2014).

Source: Survey data (2014). 
Logo foi perguntado qual era atividade que exercia antes dessa, o resultado foi o seguinte: $63 \%$ trabalhavam na atividade de pesca, 5,1\% não trabalhavam, $5,1 \%$ em outros, 3,4\% eram estudantes e 3,4\% trabalhavam como funcionário público. Esse resultado mostra que o turismo ampliou os postos de trabalhos, dando oportunidade aos residentes se inserirem na cadeia produtiva do turismo de maneira benéfica.

Diante desse resultado, verifica-se que significativa parte abandonou a atividade da pesca, descaracterizando-a, e a atividade turística tornou-se a principal. Diante disso, pode-se destacar que esta não deve ser motivo para descaracterizar a atividade da pesca, o turismo deve ser uma atividade alternativa que visa incrementar a renda das famílias.

A atividade econômica mais importante de Perobas foi considerada a pesca artesanal com 56,1\%, e depois o turismo com 43,9\%. A justificava é porque a atividade pesqueira é a principal fonte de sobrevivência da comunidade, ou seja, considerável parte dos moradores pesca para sua subsistência. A justificava para o turismo é que possibilita a inserção da comunidade na atividade turística por meio da geração de emprego e renda, e acreditam que o desenvolvimento do turismo ganhe em benefícios econômicos.

Outro tópico a ser investigado é como a participação da comunidade nas tomados de decisões sobre a APARC e como é a relação com a administração local, ou seja, procurou-se saber se os residentes sabem quem são as pessoas que tomam decisões, se há participação em alguma reunião que trate sobre os parracho, se a comunidade é ouvida, visto que a participação dos residentes locais na gestão de unidade de conservação é de suma importância, uma vez que é preciso que a gestão dê ouvido aos anseios dos moradores, e que eles possam ter conhecimento do que está acontecendo na área que pertence a eles.

Foi questionado quem para os moradores tomava as decisões sobre o que deve ser feito ou não no parracho. Com a maior porcentagem $23,7 \%$ não tinham conhecimento sobre quem é que tomam as decisões, outros mais conscientemente $18,6 \%$ citaram ser o IDEMA, e com mesma percentagem $13,6 \%$ falaram ser a comunidade ou os empresários do turismo. Assim, apenas 18,6\% sabem corretamente quem é o responsável pela UC é o IDEMA. Nesse sentido, é possível discutir que a inclusão da participação social deve ser um princípio básico na gestão da UC, e que essa seja pautada nos princípios relativos à equidade, ética e transparência nas relações entre administração local, o órgão responsável por gerir a UC e a comunidade local.

Os respondentes se mostraram representados nas tomadas de decisões sobre o parracho $(71,2 \%)$, os demais responderam de forma negativa $(28,8 \%)$, 0 que mostra uma parcela de pessoas se sentem excluídas, pois toda a comunidade deve fazer parte do planejamento da área. Ainda foi indagado quem os moradores achavam quem tomava as decisões sobre o turismo em Perobas, ver gráfico 8. 


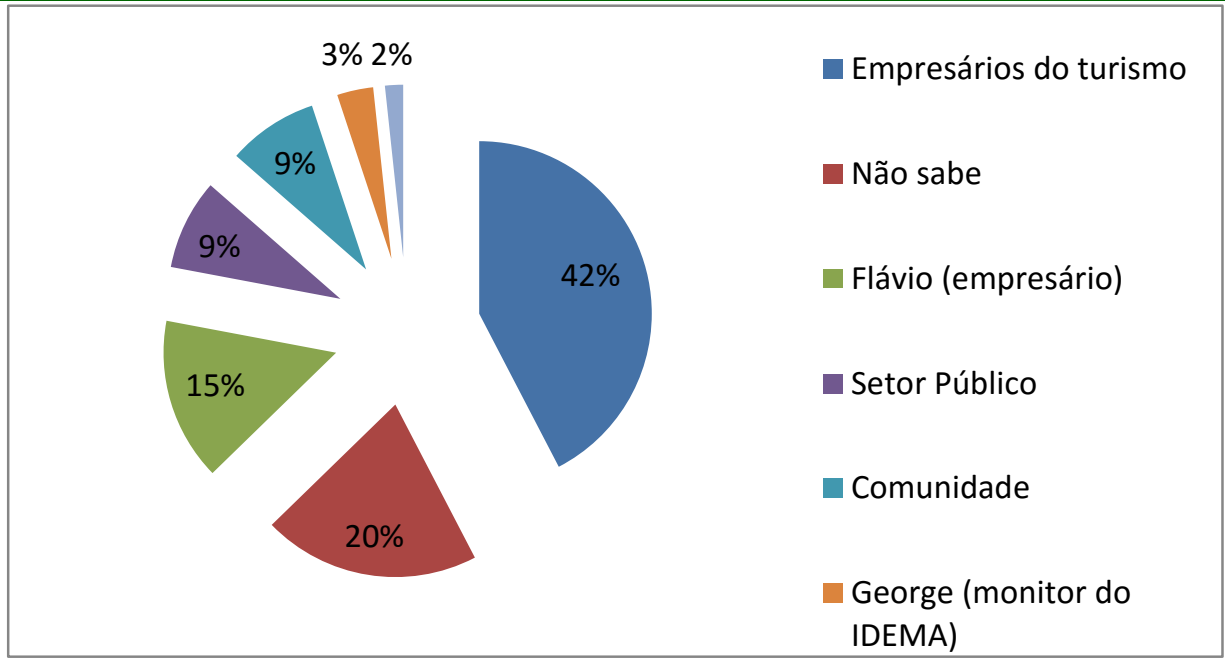

Gráfico 8: Quem toma as decisões sobre o turismo em Perobas.

Graph 8: Who makes the decisions about tourism in Perobas.

Fonte: Dados da pesquisa (2014).

Source: Survey data (2014).

Segundo os moradores quem toma as decisões sobre o turismo em Perobas são os empresários (42,4\%), nessa categoria estão incluídos os donos de lanchas que fazem os passeios, os proprietários dos restaurantes e pousadas. Identificouse que os empresários exercem uma grande influência no desenvolvimento do turismo na comunidade.

A segunda categoria reuniu aquelas respostas das pessoas que não sabe quem realmente toma as decisões do turismo na comunidade. $O$ terceiro mais citado foi o empresário Flávio (15,3\%), ele foi o precursor dos passeios aos parracho. O setor público e a comunidade já foram menos citados por eles.

Quanto à destruição/dano ao parracho 79,7\% dos respondentes acham que não está, enquanto $20,3 \%$ disseram que sim, os motivos para isso, os mais citados foram: pesca predatória, descartes de lixo inadequado, falta de educação ambiental por partes dos turistas, retirada de corais.

Por fim, foi questionado quem já tinha ido alguma reunião que tratava sobre o parracho, $81 \%$ não foi em nenhuma, onde apenas $19 \%$ participaram, ou seja, dos 59 entrevistados, 11 tiveram a oportunidade de participar de alguma reunião. Mais um resultado que mostra que o anseio da comunidade sobre as tomadas de decisões seja sobre o parracho ou o turismo é negligenciado, sendo que o motivo da não participação não foi investigado. Na teoria do SNUC visa que a participação da comunidade nas tomadas de decisões uma vez que o dialogo e o planejamento compartilhado são princípios que gerão resultados sólidos para uma gestão efetiva.

\section{Considerações finais}

A análise desenvolvida, bem como os resultados obtidos, permitiu alcançar os objetivos inicialmente definidos, norteadores do desenvolvimento do presente trabalho. Este teve como objetivo avaliar a percepção da comunidade com relação ao desenvolvimento do turismo nos recifes de corais de Perobas.

O Estado e a sociedade civil são responsáveis por garantir que as gerações futuras e a proteção da bio e geodiversidade aliado ao desenvolvimento que seja ecologicamente correto e socialmente justo. Nesse sentido, a participação da 
comunidade local no processo de planejamento e gestão é considerada um grande desafio, desse modo, a gestão participativa é importante porque pode promover saltos qualitativos na gestão das unidades de conservação por meio de ações integradas. Desse modo, uma ferramenta para o planejamento de UC é conhecer os anseios e desejos da comunidade residente, para a partir disso as tomadas de decisões serem pactuadas ao desejo comum e democrático, por isso a importância desta pesquisa, uma vez que o turismo na comunidade de Perobas está em fase inicial e para que não ocorra em outros destinos que a população local se torna vítima do turismo de maneira ruinosa.

Desse modo, foi possível concluir, quanto a importância dada aos recifes de corais pela comunidade, que o parracho possui uma grande importância para os moradores, pois é o principal meio de sobrevivência dos residentes, pois são desenvolvidas as principais atividades econômicas, como a pesca e o turismo, e é a partir dessas atividades que tiram o sustento para a suas famílias. Devido essa característica percebeu que o uso do parracho é mero recurso mercantil, meio de geração de dinheiro, negligenciando a importância que os recifes de corais têm para o meio ambiente, como berço para espécies marinhas, compostos medicinais, proteção para cota litorânea entre outros.

No tocante à visão da comunidade com relação ao turismo, constatou que alguns opinaram de forma distinta: o turismo deveria acabar por gerar impactos negativos a comunidade, de ordem social e ambiental, na qual destaque-se a entrada de drogas e a geração de lixo na praia. Como também foram apontados itens que precisam ser melhorados na comunidade, o acesso foi o item mais citado de caráter urgente. Diante disso, pode-se afirmar que como a atividade turística ainda é incipiente em Perobas, necessita de um planejamento correto, visando o seu desenvolvimento de forma ordenada, e que todos os atores envolvidos saiam beneficiados.

Além disso, foi possível constatar que a comunidade têm alguns entraves quanto o desenvolvimento do turismo e da conservação e manutenção dos recifes de corais, portanto, ver-se a necessidade de um planejamento correto e uma gestão eficaz capazes de desenvolver o turismo de forma sustentável e garantir a preservação e a conservação dos recifes de corais e que todos os benefícios gerados sejam para todos os autores, e que se torne uma ferramenta capaz de gerar qualidade de vida para a população envolvida.

Diante desse contexto, sugere que outras pesquisas sejam desenvolvidas no âmbito percepção da comunidade de modo que venha contribuir socialmente, como também para a evolução da produção cientifica do saber turístico.

\section{Referências bibliográficas}

AIRES, C. F. Análise da capacidade de inserção produtiva no turismo dos moradores da praia de Perobas/RN. Currais Novos, RN: 2012. 79 f. Trabalho conclusão de curso (Graduação em Turismo) Universidade Federal do Rio Grande do Norte. Centro de Ensino Superior do Seridó. Departamento de Ciências Sociais e Humanas. Graduação em Turismo. 
AMARAL, R. F. et al. Diagnóstico ambiental da área de uso turístico intensivo (AUTI) no Parracho de Maracajaú. IDEMA-RN, 2005.

BARDIN, L. Análise de conteúdo. Lisboa: Edições 70, 2007.

CAMPOS, S. R.; 2006. Os cinco sentidos da hospitalidade. Revista Global Turismo, v.2. Disponível em: $<$ http://www.periodicodeturismo.com.br/site/artigo/viewArtigo.php?codigo=64\&titul 0=OS\%20CINCO\%20SENTIDOS\%20DA\%20HOSPITALIDADE>. Acesso $30 \mathrm{Jul}$. 2009.

CARVALHO, S.M.S. A percepção do turismo por parte da comunidade local e dos turistas no município de Cajueiro da Praia - PI. Revista turismo em análise. ISSN 1984-4867. Vol. 21, n. 3, dezembro 2010, p. 470-493

DENCKER, A.F.M. Métodos e técnicas de pesquisa em turismo. 6. ed. São Paulo: Futura, 1998.

IDEMA. Área de Proteção ambiental recifes de corais. Disponível em: $<$ http://www.idema.rn.gov.br/Conteudo.asp?TRAN=ITEM\&TARG=944\&ACT=\&PA $\mathrm{GE}=0 \& \mathrm{PARM}=\& \mathrm{LBL}=$ Unidades $+\mathrm{de}+$ Conserva\%E7\%E3o $>$. Acesso em 24 de out 2013.

Instituto de Desenvolvimento Sustentável e Meio Ambiente do Rio Grande do Norte(IDEMA) (2007). Relatório técnico do monitoramento ambiental e de visitação nos parrachos de Maracajaú. Brasil, Natal.

KUNZMANN, A. Corals, fishermen and tourists. NAGA, WorldFish Center. Quarterly Vol. 27 No. 1 \& 2 Jan-Jun 2004.

LEÃO, Z.M.A.N.; KIKUCHI, R.K.P.; TESTA, V. 2003. Corals and coral reefs of

Brazil. In: Cortes, J. Ed., Latin American Coral Reefs, 9- 53.

MELO, R. S.; CRISPIM, M. C.; LIMA, E. R. V. O turismo em ambientes recifais: em busca da transição para a sustentabilidade. Caderno Virtual de Turismo, v. 5, n. 4, 2005. Disponível em:

$<$ http://www.ivt.coppe.ufri.br/caderno/ojs/include/getdoc.php?id=312\&

article $=105 \&$ mode $=$ pdf $>$. Acesso em: 26 mar. 2008

OLIVEIRA, E. S. 2006. Percepção dos autóctones em relação à economia, meio ambiente e ao turismo em Ilhéus - BA. In: SEMINTUR, 4., Caxias do Sul, RS. Anais, GT 10. Caxias do Sul, RS: Universidade Caixas do Sul, CD-ROM.

PEDRINI, A. G. et al. Efeitos Ambientais da Visitação Turística em Áreas Protegidas Marinhas: Estudo de Caso na Piscina Natural Marinha, Parque Estadual da Ilha Anchieta, Ubatuba, São Paulo, Brasil. OLAM Ciência \& Ecologia Rio Claro/SP, Brasil Ano VII Vol. 7 No. 1 Pag. 678 Maio/2007.

PESSOA; M.A.; RABINOVICI, A. Inserção da comunidade e as atividades do turismo. In: NEIMAN, Z.; RABINOVICI, A. (Orgs.). Turismo e meio ambiente no Brasil. Baruerri, SP: Manole, 2010.

PRATES; A. P. L; GONÇALVES, M. A; ROSA, M. R. Panorama da conservação dos ecossistemas costeiros e marinhos no Brasil. 2. ed. rev. ampliada. Brasília: MMA, 2012. 
RANIERO, L. M et al. Exploração de Recurso Ambiental: Viabilidade do Turismo Sustentável no Recife de Corais de Porto de Galinhas/Pe. Anais do XLV CONGRESSO DA SOBER "Conhecimentos para Agricultura do Futuro". Sociedade Brasileira de Economia, Administração e Sociologia Rural Londrina, 22 a 25 de julho de 2007.

RIO GRANDE DO NORTE. Decreto n. 0 15.746, de 06 de junho de 2001. Dispõe sobre criação de Área de Proteção Ambiental - APA dos Recifes de Corais. Disponível

em: <http://www.idema.rn.gov.br/contentproducao/aplicacao/idema/unidades de cons ervacao/gerados/recifes corais.asp > Acesso em: 12 ago. 2014.

SALVATI, S.S. Planejamento do ecoturismo. In: MITRAUD, S. (org.). Manual de ecoturismo de base comunitária: ferramentas para um planejamento responsável. Brasília: WWF, 2003, p. 33-38.

SANTOS, T.C.C.; CÂMARA, J.B.D. (Org.) GEO BRASIL 2002, perspectivas do meio ambiente no Brasil. Brasília: IBAMA, 2002. 447p

SANTOS, R. F. Planejamento ambiental: Teoria e Prática. São Paulo: Oficina de Textos, 2004.

SILVA, C. B. Análise da atividade turística desenvolvida na área de proteção ambiental dos Recifes de Corais - RN / 2009. 119 f. Dissertação (Mestrado) Universidade Federal do Rio Grande do Norte. Pro - Reitoria de Pós-Graduação. Programa Regional de Pós-Graduação em Desenvolvimento e Meio Ambiente/PRODEMA. Natal/RN, 2009.

VERDASCA, S. Importância das Áreas Protegidas Marinhas para a Conservação dos Recifes de Coral: Considerações Sobre a Atividade Turística no Parque Estadual Marinho da Laje de Santos, São Paulo. IF Sér. Reg., São Paulo, n. 36, p. 49-55, jul. 2008.

Wagner Araújo Oliveira: Universidade Federal do Rio Grande do Norte, Natal, RN, Brasil.

E-mail: wagnercnrn@hotmail.com

Link para o currículo Lattes: http://lattes.cnpq.br/7816610293719316

Clébia Bezerra da Silva: Universidade Federal do Rio Grande do Norte, Natal, RN, Brasil.

E-mail: clebiabsilva@yahoo.com.br

Link para o currículo Lattes: http://lattes.cnpq.br/1589690303757146

Data de submissão: 07 de julho de 2015

Data de recebimento de correções: 15 de fevereiro de 2016

Data do aceite: 15 de fevereiro de 2016

Avaliado anonimamente 